\title{
A Connectivist Perspective of the Transition from Face-to-Face to Online Teaching in Higher Education
}

\author{
http://dx.doi.org/10.3991/ijet.v8i1.2346 \\ P. Cowan ${ }^{1}$, P. S. Neil ${ }^{2}$ and E. Winter ${ }^{3}$ \\ ${ }^{1}$ Queen's University Belfast, Belfast, United Kingdom \\ ${ }^{2}$ University of West Scotland, Ayr, United Kingdom \\ ${ }^{3}$ Institute of Child Education and Psychology, Maynooth, Ireland
}

\begin{abstract}
Existing research shows a slow transition to online education by many university teaching staff. A mixed methods approach is used to survey teacher educators in three jurisdictions in the UK who have made the transition to online teaching, followed by focus group and individual interviews to triangulate the data. The eight tenets of connectivism are used as a lens for analysis. Findings reveal sound pedagogical reasons for the limited choice of online tools and tutors highlight two elements, namely, selffulfilment and their desire to continually develop as an educator, as the rationale for adopting informal professional development in the $21^{\text {st }}$ century.
\end{abstract}

Index Terms - connectivism, online pedagogy, professional development, teacher educator.

\section{INTRODUCTION}

Unlike our personal lives, where technology assists us in staying in contact with people of importance to us or increases our efficiency by saving time, the same perceived 'value' of using technology is not present in our professional life at university (Siemens, 2004). The acceptance rate and transition to online learning in universities is acknowledged to be slow with suggestions that "Faulty effort, workload and lack of reward systems may very well be a hidden factor in the perceived overall lack of acceptance [of online education]" (Puzziferro and Shelton, 2009, p.3) and without lecturers supporting and responding to pedagogical change, nothing moves forward (Bates, 2000). Indeed, without the endorsement of senior management, many university staff are reluctant to invest their time and energy in experimenting with creative uses of these new technologies needed for online teaching as indicated by MacKeogh and Fox (2009) who declare "priority in terms of funding and prestige accorded to research over teaching reduces the incentive to increase teaching commitments" (p.151). Furthermore, the negative preconceptions that exist around online education that the qualifications are less valued by the academic community, it lacks rigour and quality assurance (Weiger, 1998) thus making it easier for participants to cheat (Muirhead, 2000), have been indirectly reinforced by the lack of incentives and credit for those lecturing staff who make the transition to this mode of teaching (Betts, 1998; Bates, 2000; Shea et al., 2005; Zirkle, 2006; MacKeogh and Fox, 2009).
Regardless of whether this negativity towards online education is reliable or justified, it remains a fact that lecturing staff are slowing the pace of change in universities especially in the area of online teaching (Friel et al., 2009). It is not the technical inadequacies of lecturers which are the problem as Puzziferro and Shelton (2009, p.8) declare "Anyone can learn how to use a learning management system, but values, attitudes and beliefs are not easy to change". As Cummings et al. (2005) acknowledge "academic staff acceptance and engagement is a key factor in the successful implementation of the institutional strategy [for online learning]" so although the learning platform is easy to use, if negative attitudes exist then delays in adopting online education will ensue. The tradition of academic freedom further reinforces the strength of educationalists' opinions especially where a "strong allegiance to the face-to-face teaching model allied with a current of scepticism about e-learning, particularly around issues of quality, workload and loss of control" exists (MacKeogh and Fox, 2009, p.151). It is only through educating the lecturing staff on the virtues of online education that their values, attitudes and beliefs may change and the acceptance of online education becomes a viable and equitable alternative to face-to-face teaching.

The research reported in this paper provides a unique insight into the characteristics of lecturers who have already made the transition to online teaching. It captures their values and attitudes towards professional development in the online context. Armed with a clearer understanding of the characteristics demonstrated by these educators, this paper considers the role of connectivism (Siemens, 2004; Downes, 2007) as a way of defining the factors influencing the professional development of lecturers as online tutors thus offering a direction for tutors assuming this role in future.

\section{TRAINING LECTURERS TO WORK ONLINE}

In the past there has been dissatisfaction with the external training provided for online tutors as "faculty prefer to learn at their own pace rather than within the limited time available" when external trainers are used (Owusu-Ansah, Neill and Haralson, 2011, p.4; Donovan and Macklin, 1999). Matthew, Parker and Wilkinson (1998) also report staff concerns due to insufficient time being made available at 'hands-on' training and mentoring workshops. However it is not just cognitive concerns that are raised at 
training events but also affective outcomes such as increased technology anxiety or 'cyberanxiety' being reported and also the frustration of having 'dead' links due to websites being constantly updated (George and Camarata, 1996).

Internally delivered courses have fared no better. Staff development workshops, awareness raising programs or certificated courses may be necessary and successful in preparing faculty to initiate the move to online education and they may offer support in the creation of specific 'teaching tasks' for the learning platform however are these skills aligned to the real needs of lecturing staff? Are these programs truly preparing these educators for their role as online tutors? Puzziferro and Shelton (2009, p.5) reveal concerns about training of this type:

"Much of the training and development for ... faculty is still focused on technology, tasks, and very general pedagogical technique. This translates to a lack of active learning amongst students, possibly in part because faculty may not have the skills to create active learning environments in the context of the course and make effective use of the available technologies."

In many instances the easy-to-implement tools and strategies embedded in the learning management system are utilised (Lui, Lee, Bonk, Magjuka and Liu, 2007) rather than the students' preferred strategies of "active learning techniques such as collaboration, case-based learning, and problem-based learning" (Kim and Bonk, 2006) - strategies linked to a highly connectivist approach which is detailed later in the paper.

Yang and Cornelious (2005) highlight that online education is more than the physical uploading of teaching resources, interacting with students and promoting discussions online, it is "an arena for an interactive, deep, collaborative, and multidimensional thinking and learning environment" (Ascough, 2002). To be effective online, training is therefore necessary. Before delivering online courses it is recommended that aspiring online tutors upgrade their technical skills and remain up-to-date with technological developments (Volery, 2000); possess the appropriate instructional design skills to present the course content in an engaging and interactive way, and know how the learning platform functions so they can solve students' problems (Cuellar, 2002). Ko and Rossen (1998) and Hitch and Hirsch (2001) agree that staff training is best offered online so that tutors experience the same learning experiences as their students. Qualifications for online tuition are strongly advocated by US institutions with accreditation being required in areas such as the use of the software and learning platform, managing online courses including how to deal with providing negative feedback, prompting reluctant participants to post, addressing disruptive behaviour online, integrating online resources into the course and interacting with students in the web-based environment, before embarking on online teaching (Ko and Rossen, 1998).

\section{ADDRESSING THE CHALLENGES OF ONLINE LEARNING}

In terms of staff workload, it is accepted that "online courses take more time" not only to create but also to teach (Puzziferro and Shelton, 2009, p.6). Betts (1999) reports that the increase in workload is the factor most concerning lecturers about online education especially students' expectations of access to the lecturer almost 24 hours a day, 7 days a week. This viewpoint is extended by Piotrowski and Vodanovich (2000) who declare that "faculty cannot afford an increase in professional time commitment" and teaching online requires tutors to guide and moderate online discussions in addition to offering more support for students both technically and pedagogically than for face-to-face (F2F) teaching. Yet tutor engagement in the online community builds accountability which is valued as a measure of quality. Educationalists should be encouraged to invest their time and expertise in online pedagogical practices but this requires acknowledgement of a staff member's dedication by senior management. However frequently assumptions are made that online teaching is easy to manage as it offers more flexibility to tutors than timetabled F2F teaching sessions so this dedication often goes unnoticed. Cho and Berge (2002) stress the importance of a sound technical infrastructure, sufficient time and rewards for educators who create and deliver online courses. These rewards may include financial incentives (Picciano, 2001; Zirkle et al., 2006), or appreciation through tenure and promotion (Shea et al., 2005). Institutional level commitment to online teaching also needs to be transparent to the whole staff in terms of clearly defined goals, flexible organisational structures, the provision of resources and pedagogical support (Levin and Arefeh, 2002). However it should be noted that "while the support of senior management for change is essential, purely top-down implementation strategies will not work in the traditional academic environment” (MacKeogh and Fox, 2009, p.152).

\section{CONNECTIVISM}

By adopting a model of training which parallels the process of online learning, lecturers who have not already experienced an online course, which may be a large proportion of them, have the opportunity to engage in this unique learning experience in the context of their own university systems. It has been widely accepted that technology supports a constructivist approach to learning and models, such as Salmon's (2003) five stage hierarchy for online learning or Laurillard's (2008) framework for technology-enhanced learning which traverses instructionist, constructionist, social and collaborative models of learning, have confirmed this viewpoint. Nevertheless, constructivism is limited in its representation of the more widespread and less controlled modes of learning currently being utilised in the virtual learning environments. Indeed, a connectivist model is gaining momentum in the research debate especially for the 'digital learner' who maximises the potential of social networking sites and Web 2.0 pedagogies. Connectivism was defined by Siemens (2004) as "the integration of principles explored by chaos, network, and complexity and self-organisation theories" where the core elements of learning are constantly shifting relative to the new information being acquired and knowledge being constructed between the appropriately inter-connected individuals. Downes (2007) simplifies the idea to knowledge that is distributed across a network of connections and the process of learning is the ability to construct pathways to navigate across those networks. Like Siemens (2004), Downes' definition places the primary focus on the connections rather than the knowing. Connectivism starts with the individual and is most effective when there are 'hubs' (well-connected 
PAPER

people) who can sustain the knowledge flow in multiple directions (Siemens, 2004). Siemens (2004) defines the main tenets of connectivism as:

- "Learning and knowledge rests in diverse opinions;

- Learning is a process of connecting specialised nodes or information sources;

- Learning may reside in non-human appliances;

- Capacity to know more is more critical than what is currently known;

- Nurturing and maintaining connections is needed to facilitate continual learning;

- Ability to see connections between fields, ideas, and concepts is a core skill;

- Currency (accurate and up-to-date knowledge) is the intent of all connectivist learning activities;

- Decision-making is itself a learning process. Choosing what to learn and the meaning of incoming information is seen through the lens of a shifting reality. While there is a right answer now, it may be wrong tomorrow due to alterations in the information climate affecting the decision.”

These skills closely resemble those of an 'active learner' which are typified by "lively debates between instructor and students, peer-to-peer discussions, reflective writing and team work" (Kassens-Noor, 2012, p. 9) combined with "thoughtful engagement” (Drake, 2012, p. 41) which motivates learners to take responsibility for their own learning decisions as evidenced in enquiry learning or discovery learning, the 'pure' active learning strategies (Drake, 2012). The above eight tenets of connectivism will be pertinent for understanding the analysis later in the paper.

Based on these eight tenets, the skills required to be an effective learner in this environment are largely independence, motivation and socialisation in diverse societies. However it is possible to be too connected. For some, the sheer volume of information available can be overwhelming leading to learners struggling to identify the relevant information from the irrelevant (Surowieki, 2005). Yet Surowieki (2005) purports there is wisdom in crowds and that interaction is key to intelligence. But it is acknowledged that connectivist learners need to possess skills such as the ability to find, synthesise and apply the knowledge with a high level of independence, they need to identify their own learning needs and seek information, participating in a variety of online groups as necessary. Connectivist learners must also excel at filtering information and making electronic contributions which deepen their own understanding of the content area and develop their retrieval skills (Anderson and Dron, 2011). Although the online tutor collaborates electronically with the learners to outline and produce the subject matter and assessments, the attitude of the tutor is almost irrelevant. Teaching presence in a connectivist environment focuses on teaching by example, and includes learners teaching tutors as well as each other. For this reason, connectivist pedagogies often appear to be at odds with the accepted models of instruction, curriculum and assessment (Siemens, 2004).

Using the above definition of connectivism, this paper investigates its role in educationalists' work and how connectivism is useful in understanding the professional development of teacher educators as online tutors.

\section{The Aims OF THE STUDY AND RESEARCH QUESTIONS}

Active learning strategies dominate much of the online teaching both formally and informally in the education sector at present (Palloff and Pratt, 1999). Indeed, Web 2.0 tools offer increased opportunities for interactivity, engagement and self or peer assessment making the use of connectivism as a lens through which to analyse teacher educators' role online, a preferred choice. Thus connectivism is the theoretical framework underpinning this study and the research aimed to determine the extent to which tutors, who have made the transition from face-to-face to online teaching, utilise the tenets of connectivism as listed above either themselves or in their online courses. This investigation is guided by the following research questions:

- To what extent are the active learning strategies which map to connectivist tenets being used in online teaching?

- Which elements of connectivism best explain online tutors' professional development?

- Is there evidence that the further professional development needs of online tutors can be explained using these connectivist tenets?

\section{MethodolOgY}

A pragmatic paradigm of inquiry offered the researchers the opportunity to collect data from a real problem using a mixture of qualitative and quantitative approaches and was deemed the "most appropriate to use for $e$ learning research” (Phillips et al., 2012, p.77). As Kozma (1994) affirms, pragmatism is capable of coping with the complexities inherent in e-learning contexts in addition to promoting discovery within the learning context and seeking to identify causal relationships, by identifying the nature of reality of being an online educator.

An online survey was used to capture an overall picture of online educators delivering courses in third level institutions in Northern Ireland, Scotland and the Republic of Ireland. Due to the online nature of the respondents' work, there were minimal concerns about the use of the online questionnaire as it was deemed to be the more accessible and 'natural' environment for the target population. Closed questions were used to capture biographical details, rating questions determined the level and frequency of use of the various online technologies while open-ended questions offered opportunities for the respondents to provide extensive insights into their pedagogical practices online through self-reporting. Volunteers from the survey respondents were sought for the focus group and individual interviews to be conducted via Skype.

\section{A. Sample}

Purposive sampling was used to identify those online tutors from Northern Ireland, Scotland and the Republic of Ireland who delivered more than $80 \%$ of their course online on the basis that these online educators were 'information-rich' with respect to the aims of the study (Patton, 2001). Initial contact was made to confirm their interest in the research and approximately 70 online tutors were sent an email with the link to the consent form and 
online survey. Complete responses were obtained from a total of 46 tutors (66\% response rate) and half these respondents expressed a willingness to be involved in the qualitative stage either as part of the focus group or individual interviews. A subgroup of 15 tutors representative of the three jurisdictions, with a variety of years of experience teaching online and from different backgrounds were interviewed before data saturation was reached. The survey data was analysed using SPSS and due to the small number of respondents in each jurisdiction, it was considered inappropriate to make national comparisons from the data as it was not generalizable. The next section discusses the collective results from the three countries which portrays the reality of online education in higher education institutions within these three countries in the UK. Connectivism was used as the lens through which the interview data was analysed and reported in the following section.

\section{ANALYSIS AND RESULTS}

Of the 46 respondents to the online survey, more female (72\%) online tutors than male (28\%) tutors replied. Three quarters of the respondents were aged 45-64 years of age indicating a more mature population of online tutors employed in this field. None of the respondents were under 25 years of age and only 4.3\% were aged 25-34 years. The majority of tutors had taught online between 1 and 10 years with the modal number of years of online teaching, 4 years and a mean of 5.74 years (s.d. $=3.17$ years). The males had more experience of being an online tutor (mean $=7.2$ years) compared to the females (mean $=$ 5.1 years) however two respondents had been innovators in the online world having already accumulated 15 years of online teaching experience each. Over $80 \%$ of online tutors were teaching on award-bearing courses such as Diploma, Masters or Chartered Teacher while only 45\% delivered non-award bearing courses such as in-service training or on-going professional development courses. $13 \%$ of online tutors were involved in both types of courses and there were equal distributions of males and females teaching the non-award bearing courses.

Just over half (52.2\%) of the respondents had taken an online course themselves as a student, the majority of whom were females (75\%). The respondents were generally positive about their own ICT confidence and competence with over half of the group selecting High in both cases although the mean scores reveal that they are slightly more competent (mean $=1.44$ ) than they are confident (mean=1.49) with males being slightly more positive than females.

In terms of the rationale for moving to online teaching, 75.5\% of respondents reported they had moved by personal choice, while $53.3 \%$ declared it was an institutional requirement. It would therefore appear that respondents made the choice of when to move to online teaching providing them with the level of personal choice within a longer-term institutional requirement to make this transition. Similarly a mixture of ready-made and own design courses was used with $60 \%$ of participants indicating they were using both types in their current teaching. Further clarification of this response revealed that departmental or group collaboration for the content of the course had occurred so the respondents did not view it as entirely their own creation; for other tutors, shared courses existed supported by co-teaching online.

\section{A. Active learning strategies used}

The respondents were familiar with a range of technologies for work and pleasure. The majority (85\%) were familiar with virtual learning environments (VLEs) such as Moodle, WebCT and BlackBoard. Almost $70 \%$ of them used Skype while $46 \%$ participated in social networking (FaceBook, Twitter etc.) and $41 \%$ were users of videoconferencing. Collaborative tools such as wikis and blogs were used by $28 \%$ and $22 \%$ of respondents respectively while only one person had experienced Immersive Virtual Worlds such as Second Life. For both males and females, the top technologies used for work and/or pleasure were VLEs and Skype. In third place the males preferred the shorter, more informal messaging approach of social networking such as FaceBook and Twitter compared to the females who ranked the formal interactions associated with video-conferencing in third place. Other written modes of collaboration were favoured by the males including wikis and blogs, a pattern not present for the female online tutors.

The respondents were asked to rate the importance of 15 elements of online environments on a scale of High, Medium, Low or Unknown (if they were unsure of the feature listed). The items ranking most often in the High category were the asynchronous uses of VLEs such as Discussion forums $(90.7 \%)$, asynchronous communication (83.7\%), email (72.1\%) and blended learning (46.5\%) as shown in Figure 1a. The use of Live Classroom was most frequently reported in the Medium category by $27.9 \%$ of respondents. The Low category contained the real-time interactive tools including synchronous communication (48.8\%), video-conferencing (39.5\%), instant messaging (37.2\%) and online voting or polling (44.2\%). Noninteractive delivery of materials was also rated Low such as powerpoint (with voice-over $(44.2 \%)$ or without voiceover $(46.5 \%)$ ), a non-interactive online course $(58.1 \%)$ and calendar (1\%). Wikis (44.2\%) and blogs (39.5\%) were both reported as Unknown. This data is summarised in Figures 1a and 1b which reveals the match between the unknown functionality of VLEs and their perceived lack of importance.

It would therefore appear that the real-time interactivity and collaboration being afforded online does not rank highly with these current online tutors however active learning through the use of asynchronous methods is dominant.

When asked to consider the same 15 elements and rate them according to their frequency of use, a more striking picture results as shown in Figure 2. As indicated by the dark proportions of the bars on the left-hand side of the

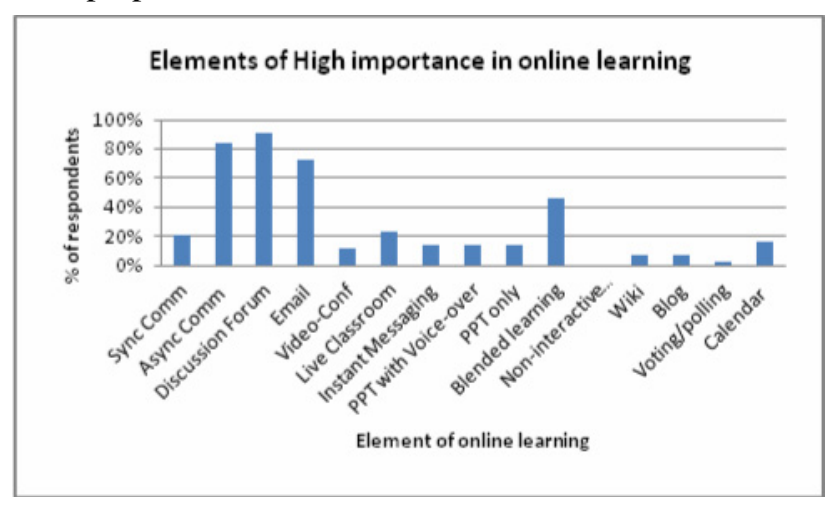

Figure 1a Elements of High importance in online learning 


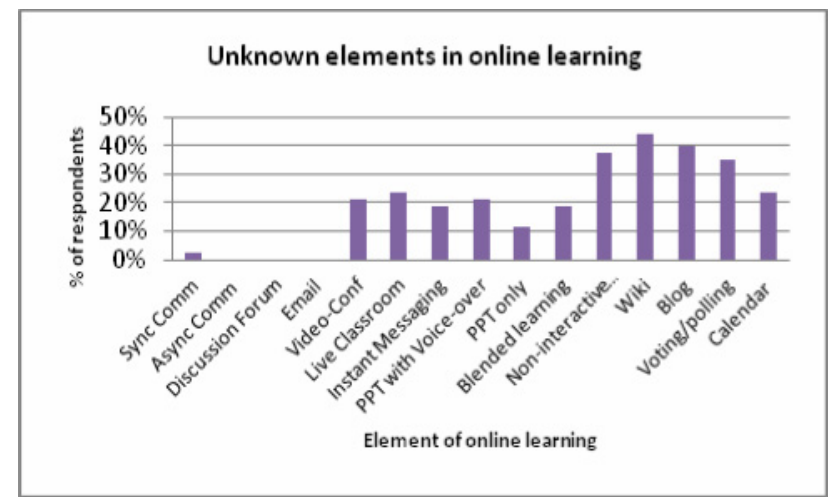

Figure 1b Unknown elements in online learning

chart, over $70 \%$ of respondents reported High frequency of use of discussion forums (88.4\%), asynchronous communication (74.4\%), and email (69.8\%). Low usage of synchronous communication (51.2\%) was revealed (in the topmost bar) while there was no reported use of the remaining features - as indicated by the longer grey sections on the right-hand side of the chart in Figure 2.

It is apparent from this data that the tools most commonly associated with online collaboration such as wikis, blogs, video-conferencing, instant messaging and online voting/polling were unused by over $50 \%$ of tutors. The active learning supported by these online Web 2.0 tools was therefore reduced in many of the online courses being delivered. It is not known whether these online tutors were unfamiliar with these facilities and how to use them effectively, or whether the outcome reveals a more pertinent issue such as restrictions in course design or institutional policy which does not advocate the use of these Web 2.0 tools.

\section{B. Assessment methods in online courses}

Like the course design, the assessment methods used by online tutors appear confined to the conventional written assignments (89.5\%), tutor assessment (76.3\%) and ongoing assessed tasks and/or reflective journals (55.3\%) generated throughout the course. These choices may be a direct result of the requirements of award-bearing courses rather than the tutor's perception of the most appropriate method of assessing students' learning. Online tests (26.3\%), e-portfolios and peer assessment (31.6\%) were the least used assessment techniques, while around 40$50 \%$ of respondents used online quizzes, individual or collaborative group projects/presentations or self assessment as shown in Figure 3.

When asked about the frequency of use of these assessment methods, the pattern of black bars (on the left-hand side of Figure 3) reflected the priorities identified above with written assignments remaining High frequency for $71.1 \%$ of respondents, and tutor assessment being dominant for $57.9 \%$. On-going assessed tasks were also categorised as High frequency use by $39.5 \%$ of online tutors. As Figure 3 illustrates, over $60 \%$ of respondents report their use of online tests, e-portfolios and peer assessment being non-applicable (the grey sections of the right-hand side of the chart) while online quizzes and collaborative group projects/presentations were considered not relevant by $55.3 \%$ and $50.0 \%$ of respondents respectively. Similarly, no use was made of individual projects/presentations or self-assessment by $44.7 \%$ of online tutors, while $39.5 \%$ of them reported no use of reflective journals.

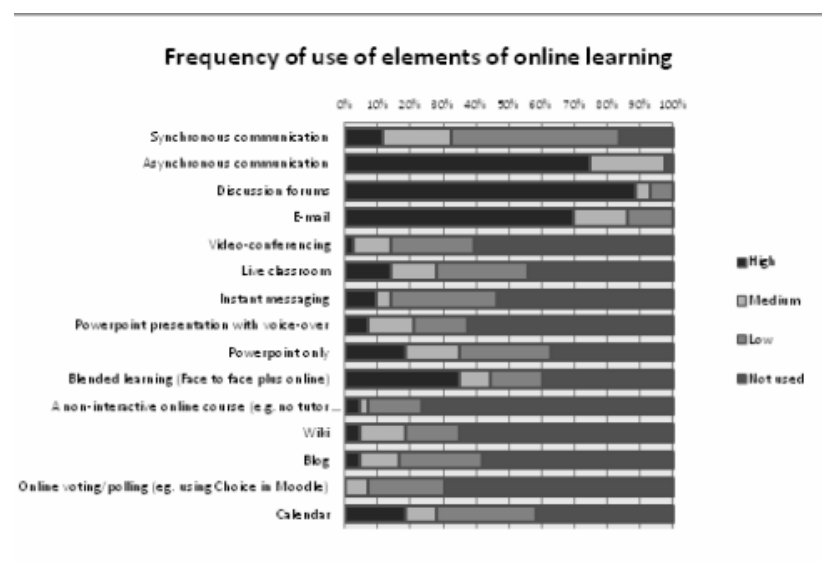

Figure 2. Frequency of use of the elements of online learning

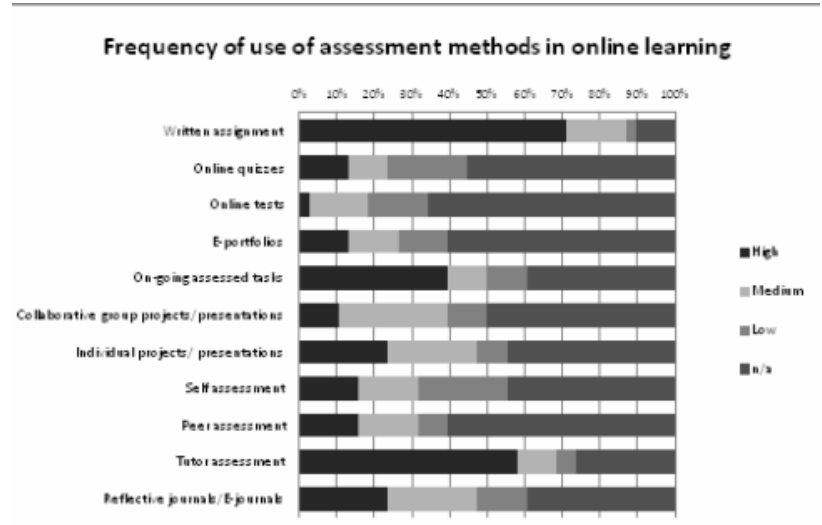

Figure 3. Frequency of use of assessment methods in online learning

It could therefore be argued that although active teaching strategies exist in the online courses, albeit mainly via asynchronous communications rather than in real-time or using Web 2.0 tools, the assessment methods show no indication of a transition towards the more authentic, application of knowledge in real-life contexts as captured through e-portfolios or job-related projects. Moreover, the influence of institutional restrictions on the access and availability of online features is also constraining the structure and content of the online courses and associated activities which is further exacerbated in the assessment methods being adopted. The most interesting outcome from the survey however, is the widespread nature of these constraints especially when higher education is already lagging behind in the move to online education (Owusu-Ansah et al., 2011).

\section{Online tutors' professional development}

The transition from face-to-face (F2F) to online teaching was reported as a positive experience for $77.1 \%$ of respondents, the remainder indicated a neutral attitude towards the change. When discussing their continued professional development (CPD) as online tutors during the focus group interview (denoted by FG) or individual interviews (denoted by I), the tenets of connectivism (Siemens, 2004) surfaced in various formats.

\section{1) Diverse opinions}

Some tutors focused on the importance of diverse opinions declaring that you "learn lots from students. ... It's great working with adults - the new information, new ideas of ways of working, ..." (Male, I). For many tutors 
collaboration and co-operation is key to their approach to professional development as highlighted by the statement that "Good training is vital for online learning and there is a need to have a team internally [in School] who can support each other on an as-needed basis" (Female, I). Collegiality through peer support on a regular basis was noted as an effective mechanism for CPD as was dissemination of good practice including "more dialogue with peers around e-learning" (FG) and getting inspiration from those in other Schools through sharing reflections.

\section{2) Connecting specialist nodes}

The importance of learning to work collaboratively with other tutors, possibly as co-tutors with complementary expertise, is seen as a priority by a subgroup of online tutors, as is assessing student work online using authentic assessment opportunities. This holistic approach to CPD reinforces the continued commitment of online tutors to supporting, guiding and sharing ideas with each other. As one tutor stated "the community of practice model is perfect for CPD for tutors!" (Female, I)

It is clear that CPD is "driven by the person" (FG) and their desire to improve and extend the repertoire of online skills being implemented in their courses. For these people, being able to discuss and share ideas with others is a key to broadening the range of experiences used to empower their learners. Capacity-building within and across institutions is therefore important. Modelling good practice and having the facility to open the course to others (as viewers) assists in the process of innovative course design.

\section{3) Learning residing in non-human appliances}

Many of the currently used online collaborative tools are considered not to be developed for educational purposes. Instead they are deemed to be for "community and socialising and research...VLEs are the exception and they are clunky" (Female, I). So this raises the question for CPD: how does one focus on curriculum development which is inclusive of the technology? The key factors identified are "tutor, learning, prior background of the learner, and technology itself” (Female, I). This may be captured as Technological, Pedagogical And Content Knowledge or the TPACK model (based on PCK of Shulman, 1986). It is not the content that is important but the mechanism to facilitate the process of learning, how the technology - VLE - facilitates the learner's needs. As one online tutor declared "The last thing kids need from me is information which used to be the first thing they needed!" (Female, I). Instead the online course should encourage students to engage in "critical thinking and [consider the] implications of decisions" (FG).

From the online tutor's perspective, looking at the teaching continuum from Sage-on-the-Stage (at one end with full control) to being a Facilitator or Guide-on-theSide (with minimal input) (King, 1993), it has become accepted that $21^{\text {st }}$ century teaching processes need to be located somewhere near the centre of this continuum with the online tutor acting as a co-learner or 'Meddler-in-theMiddle' (McWilliam, 2008). But taking this stance requires from teachers "the need to change; we should now learn to create something" (FG) such as tutors taking control of creating their own online courses to deliver the content in a pedagogically sound way.

\section{4) Capacity to know more}

Online tutors are constantly aware of the need to sustain their capabilities and familiarity with the latest technological innovations. There is no clear boundary between their personal development and their professional development as a tutor. Scholarship is key to these tutors who recognise the importance of "finding new ways for students to interact with one another as well as the tutor" (FG) and "keeping up to date with developments" (Female, I) in terms of refreshing their courses and upgrading the pedagogical approaches embedded in the online activities to include the new Web 2.0 tools such as wikis, blogs, voting and live classrooms as they become available within the virtual learning environments hosting the courses. Specific training needs were stated such as ongoing training and up-skilling to match current developments in online pedagogy. Assessment online, authentic assessment opportunities and giving feedback through effective questioning are other areas where tutors want more up-skilling. Specific skills development was mentioned in relation to moving from audio to video delivery indicating the effective use of self-evaluation and reflection on the course structure and content combined with tutors' capacity to learn and trial more challenging processes.

5) Nurturing and maintaining connections for continual learning

In some cases the nurturing of connections for lifelong learning was conveyed by tutors as "raising my game" (Female, I) while for others it reflected the shift in society towards a more informal, collaborative partnership between learners where study and life blend seamlessly into one another. For one online tutor " $C P D$, continued professional development, is a way of life and something I need to do" (Female, I) indicating a personal desire and commitment to be engaged, try new ideas and "give something back to the profession" (Female, I). Connections varied from social networking options such as FaceBook and Twitter, to more traditional types of networking such as being part of an online community of practice, either as an active participant or as a casual observer in learning environments such as TED.

\section{6) Seeing connections and interrelationships}

Hearing about other tutors' experiences online, seeing ideas implemented in practice and sharing research findings are all part of the on-going professional development of the online tutor. However it was also recognised that "you don't know what you want" (FG) at times so opportunities to observe other colleagues teaching online could offer inspiration to fellow online tutors and initiate an interest in trialling a new approach in their online course. In addition immersion in other online courses is often needed to uncover the gaps in tutors' own subject knowledge and expertise of course design. It was agreed by the FG that working with others outside your own area of expertise also offers opportunities for the cross-fertilisation of ideas and pedagogies.

\section{7) Currency of knowledge and skills}

Ways to keep up-to-date vary with some online tutors opting for the traditional methods of relying on reading the research literature in books and journals, while others enjoy the online materials such as video in TED as a less formal mechanism for learning. Experiential learning was 
also advocated as a good gauge for determining the effectiveness of delivery of materials using emerging technologies, such as FaceBook and Twitter, and also acting as a template or model for online courses to embed in their own course structures. National conferences were acknowledged to be beneficial to CPD especially if other tutors were sharing their experiences online, or demonstrating how ideas are implemented in practice. Sharing research findings as an element of scholarship are all part of the on-going professional development of the online tutor.

8) Decision-making and changing realities.

For some, the changing reality of CPD from day release and in-service courses to the participation in online professional development such as webinars and live classrooms has been a challenge in itself. In addition, the twilight nature of these courses means they have to be self-funded and may be seen to intrude into home life. Decisions to partake in CPD of this format may result in a negative impact on take-up rates. For other tutors professional development requires them to understand the role and context in which their learners are working so that empathy, advice and support can be provided in an honest and accepted manner. An awareness of "not living their problem" (Female, I) is felt as a disadvantage by the online tutor and so compensatory strategies are used to "bridge the gap" (Female, I).

Other elements of CPD arose in the discussion and have been added to the existing list of connectivist principles for discussion.

\section{9) Self-fulfilment - CPD for the mature online tutors}

Self-fulfilment is an important element of CPD. As one online tutor declared "The experience is fulfilling; it gives me something I don't get elsewhere." (Female, I). Like mentoring, the more mature online tutors view their role as providing them with an outlet through which they can "give something back to the profession" (Female, I) by allowing other online tutors to learn from their experiences. Another tutor contrasts his online world with his day job saying "I enjoy working with adults, it's very different from kids, they are nice. ... There's progression once you get older. It's very refreshing to be tutoring online, it helps me going off to school. ... I feel I am keeping in touch and how you feel is important and enjoyable. It comes from the heart." (Male, I) The feelings of self-fulfilment come in a variety of packages as illustrated above, however in all cases, being an online tutor appears to be a heart-warming experience for them and one which they may feel will live on when they are no longer participating.

10) New forms of continued professional development (CPD)

The perception of what constitutes CPD in the $21^{\text {st }}$ century was noted as a barrier for many of the online tutors being interviewed. The perceived notion of CPD being formal courses attended either F2F or online, where attendance is registered, evaluations completed and often certification attached is now being challenged in light of the ubiquitous nature of online learning. This mismatch between traditional CPD and current modes of learning is resulting in a lack of recognition of the impact of informal learning as an acceptable and often valuable form of CPD. Social networking has re-shaped CPD as was previously conceived and a recognition is emerging that the role of online forums, twitter feeds, RSS feeds and sharing websites via social bookmarking are skills needed by employers. Often "online learning is a barrier to itself with assumptions being made that online courses are easier" (Female, I). The cost of online training can be prohibitive as employers may prefer to fund F2F courses which are more easily monitored and have pre-defined release times.

Finally informal learning was considered 'the elephant in the room' and the culmination of connectivism on a grand scale. Inquisitive people can search out and join online groups to further enhance their expertise. There is a considerable amount of informal online learning taking place daily without any recognition of its role in professional development. Informal learning is the key to determining how people learn online, explaining why some people have a desire to search out like-minded individuals, join their online discussion forum and become part of that community of practice. In fact, "communities of practice are probably diametrically opposed to formal learning" (Female, I) and FaceBook was considered by online tutors possibly to be the obvious example of how an informal community of practice can be established and sustained without the context of any formal learning.

\section{DISCUSSION AND CONCLUSIONS}

As indicted earlier, this investigation was guided by the following research questions:

- To what extent are the active learning strategies which map to connectivist tenets being used in online teaching?

- Which elements of connectivism best explain online tutors' professional development?

- Is there evidence that the further professional development needs of online tutors can be explained using these connectivist tenets?

Unlike Christie and Jurado (2009) who found lecturers felt compelled to incorporate as many of the technological tools as possible into their online courses, this survey revealed that asynchronous communication dominated the online pedagogies for the courses and there were High levels of usage of discussion forums and email as key channels of communication for these tutors. Live classroom was ranked of Medium use indicating the 'lecture style' of presenting new ideas and concepts was preferable to the more open and interactive discussions typical of video-conferencing, or instant messaging as noted by Oren et al. (2002). Asynchronous online collaboration and group discussions were utilised by the tutors to engage and motivate the learners to share their experiences and generate theory from their practice. By co-operating on various activities as indicated by the presence of on-going tasks and/or reflective journals, knowledge was being constructed in contexts relevant to the learners while the contributions and reflective evaluations were also being used for assessment purposes in addition to the more traditional and dominant use of the teacher-assessed written assignment.

During the participant individual interviews or focus groups, reasons for the low level of usage of synchronous communication strategies included the students' expectations of an online course having no time restrictions and 
PAPER

the any-time/any-where nature of the course was the rationale for choosing this online mode of delivery. Consequently it would be difficult to introduce expectations that all students would be available online at specific times for video-conferencing or real-time discussions. In addition, the flexibility that is inherent in online courses in terms of studying around work commitments is removed if requirements for synchronous communication prevail.

Finally, the global nature of online education means that time zones may restrict the feasibility of synchronous communication and so a 'trade-off' is needed between the forms of communication and the spread of participants worldwide. It was considered to be of more value to have input and perspectives from a breadth of participants internationally rather than the ability to meet in real-time virtually. Based on these constraints and the importance the tutors' assigned to the process of learning over the utilisation of the functionality available on the VLE platform, the level of interactivity in the online courses was appropriate for the purpose of the course, resulting in valuable discussions in the forums which facilitated knowledge sharing and construction (Salmon, 2003). Where live classrooms were recorded and available for playing back, the atmosphere of a real-time session could be captured for those absent from the experience.

The second research question considered the features of the connectivist framework which impact most on tutors' professional development. This study revealed that the eight features proposed by Siemens (2004) did exist in the lived experiences of these online tutors. Despite the ethos of collaboration and sharing typified in online learning, from the tutors' perspectives, in the main the process of professional development is more individualistic and person-centred. If the connectivist tenets are adopted at departmental level, then a whole staff emphasis on developing connectivism in teaching would prevail however this lack of reciprocity in support for online learning further reinforces the earlier discussions regarding the stigma attached to online courses (Betts, 1998; Bates, 2000; Shea et al., 2005; Zirkle, 2006; MacKeogh and Fox, 2009).

From the focus group and individual interviews, the online tutor was revealed as the clear driver of the process, reflecting on their own performance and setting goals to continually strive for more modern and interesting uses of the technology - skills proposed by Volery (2000). As Deubel (2003) confirms, it is the online tutor's attitude, motivation and true commitment that generates quality online instruction. Online tutors indicated the value they place on viewing other tutors' courses to get new ideas and approaches, and also the importance of training in the new functions added to VLEs, and support in 'raising their game'. As Pankowski (2004) revealed, more opportunities for technical training exist compared to pedagogical guidance in universities. For this reason, it is imperative that online tutors participate fully in peer review and mentoring processes to assist in the sharing of new ideas and effective pedagogical practices. The tutors in this study reported a sense of enjoyment when being part of an online course and forming new allegiances with other online tutors through sharing experiences and capacitybuilding.

Two new perspectives related to the connectivist viewpoint emerged from the interviews: firstly, the importance of self-fulfilment when acting in this mentorship role and leaving a legacy for future generations of online tutors, and secondly, an acknowledgment of the changing format of professional development and its potential to encroach on personal time and space resulting in important decisions needing to be made about 'costs' in terms of time and money. Both aspects emerged most predominantly from the focus group and individual interviews as the teacher educators reflected on their perceived role as online tutors and the impact they had on other learners. The high level of social responsibility they feel to the wider teaching profession, whether F2F or online, is characteristic of connectivism where they view themselves as nodes in the learning process and recognise the importance of their role as a conduit connecting others, often with diverse opinions, and nurturing relationships to facilitate continual learning. Their capacity and desire to know more and continually develop themselves as online tutors evolves from their teaching roots as teaching is a reflective profession. The major shift for online CPD however is the recognition (by senior management) that formal methods of CPD in timebound and expert-led sessions are outdated. Current innovative educational practices emerge from informal exchanges with others from a variety of disciplines and may occur anytime, anywhere making collaboration through being wellconnected, the goal for future educators. For this reason, there should be acknowledgement of the 'costs' to the online tutor in terms of personal time and commitment. These additional elements relate to the third research question, further professional development in using connectivist principles.

The more informal approaches to CPD as offered by the ubiquity of technology and the blurring of the boundaries between work and life, facilitates online tutors' desire for self-development, capacity-building and improved scholarship. It should be remembered that an online tutor's work is never done - committed tutors are available online almost 24/7 due to the pleasure they gain from helping others and being part of an ever-changing community of practice. For these tutors, the spirit of connectivism is embodied in their being, and the increasing ease with which they can access the online course from mobile technologies which support their connectivist beliefs and offer the self-fulfilment they desire from their mentoring role as an online tutor.

This research aimed to provide an insight into the profile of teacher educators in the UK as online tutors and their attitudes and beliefs which assisted them in making the transition from F2F to online teaching. Although the sample size is relatively small - 46 tutors - and a restricted number of UK jurisdictions were sampled, the findings indicate a clearly justified approach to online education taken by online tutors which offers active learning in asynchronous contexts to accommodate the international audience they aim and in some cases, do attract on their courses. Although the restricted use of the available functionality in VLEs appears to contradict the 'active' stance being portrayed, the online tutors' commitment to supporting, guiding and extending learning via the discussion forums counterbalances any concerns raised. The interviews capture the essence of an effective online tutor as someone who is connected, innovative, and continually striving to learn more. They accept the informal nature of CPD in the $21^{\text {st }}$ century in which their work and their personal life converge, as they are enthusiastic 
about continuing to grow as a professional and a person, and view this as self-fulfilment.

It is acknowledged that future research addressing all jurisdictions in the UK would determine if country specific patterns exist due to separate funding arrangements and educational initiatives which may influence online education and expectations from higher education institutions. As it stands this study extends the existing literature by revealing the specific beliefs and attitudes of this group of teacher educators who are considered innovators by senior staff within their institutions driving forward online teaching and learning to a global market. However it is acknowledged that other groups of educators, such as those involved in engineering or science, may utilize a different tool set within the VLE's functionality as a consequence of the need to have real-time chat on core theoretical ideas or complex concepts. Nevertheless the intention of this study was to reveal the extent to which experiences from F2F pedagogy impacted upon or challenged teacher educators' ability and skills to teach online.

By applying connectivist principles to these online tutors, aspects of good practice in their online pedagogy were captured in addition to identifying areas for future development and support to sustain the commitment to online learning which is so clearly portrayed in these online tutors' work ethic. Future online tutors are advised to seriously consider the eight principles of connectivism prior to embarking on online teaching and to ensure their online practices evoke the additional level of selffulfilment, passion and enthusiasm needed to continue to develop as a professional and innovator of technologyenhanced learning.

\section{ACKNOWLEDGMENTS}

Grateful thanks are extended to the Higher Education Academy for Education (ESCalate) in UK for funding this research.

\section{REFERENCES}

[1] Anderson, T. and Dron, J. (2011) Three generations of distance education pedagogy. International Review of Research in Open and Distance Learning, 3, 12, 80-93.

[2] Ascough, R. S. (2002) Designing for online distance education: Putting pedagogy before technology. Teaching Theology and Religion, 5, 1, 17-29. http://dx.doi.org/10.1111/1467-9647.00114

[3] Bandura, A. (1977) Social learning theory. Englewood Cliffs, NJ: Prentice-Hall.

[4] Bates, A. W. (2000) Managing technological change: Strategies for college and university leaders. San Francisco, CA: JosseyBass.

[5] Betts, K. S. (1999) Factors influencing faculty participation in distance education in post-secondary education in the United States: An institutional study. Dissertation Abstracts International, DAI-A59/07.

[6] Cho, S. K. and Berge, Z. L. (2002) Overcoming barriers to distance training and education. Education at a Distance, 16, 1, 26-34.

[7] Christie, M. and Jurado, R.G. (2009) Barriers to innovation in online pedagogy. European Journal of Engineering Education, 34, 3, 273-277. http://dx.doi.org/10.1080/03043790903038841

[8] Cuellar, N. (2002). The transition from classroom to online teaching. Nursing Forum, 37, 3, 6-13. http://dx.doi.org/10.1111/ j.1744-6198.2002.tb01005.x

[9] Cummings, R., Phillips, R., Tilbrook, T. and Lowe, K. (2005) Middle out approaches to the reform of university teaching and learning: champions striding between 'top-down' and 'bottom-up' approaches. The International Review of Research on Open and Distance Learning, 6, 1.
[10] Deubel, P. (2003) Learning from reflections - issues in building quality online courses. Online Journal of Distance Learning Administration, 6,3 .

[11] Donovan, M. and Macklin, S.(1999). The catalyst project: Supporting faculty use of the Web ... with the Web. Cause/Effect, 22, 3 ,

[12] Downes, S. (2008) An Introduction to Connective Knowledge. In Hug, Theo (Ed.) (2007): Media, Knowledge \& Education - Exploring new Spaces, Relations and Dynamics in Digital Media Ecologies. Proceedings of the International Conference held on June 25-26, 2007.

[13] Drake, J. R. (2012) A critical analysis of active learning and an alternative pedagogical framework for introductory Information Systems courses. Journal of Information Technology Education: Innovations in Practice, 11, 39-52

[14] Friel, T., Britten, J., Compton, B., Peak, A., Schoch, K. and VanTyle, W.K. (2009) Using pedagogical dialogue as a vehicle to encourage faculty technology use. Computers \& Education, 53, 33-307. http://dx.doi.org/10.1016/j.compedu.2009.02.002

[15] George, G. and Camarata, M.R. (1996). Managing instructor cyberanxiety: The role of self-efficacy in decreasing resistance to change. Educational Technology, 36, 4, 49-54.

[16] Hitch, L. P. and Hirsch, D. (2001) Model training. The Journal of Academic Leadership, 27, 1, 15-19.

[17] Kim, K. and Bonk, C. J. (2006) The future of online teaching and learning in higher education: The survey says... EDUCAUSE Quarterly, 29, 4, 22-30.

[18] King, A. (1993) From Sage on the Stage to Guide on the Side. JSTOR: College Teaching, 41, 1, 30-35. http://dx.doi.org/10.1080/ 87567555.1993.9926781

[19] Ko, S. S. and Rossen, S. (1998) Faculty development for online instruction: Two models for effective teaching. Paper presented at 1998 Third Annual TCC Online Conference. http://leahi.kcc.hawaii.edu/org/tcon98/paper /ko.html [last accessed 12 June 2012].

[20] Kozma, R. B. (1994) Will media influence learning? Reframing the debate. Educational Technology Research and Development, 42, 2, 7-19. http://dx.doi.org/10.1007/BF02299087

[21] Laurillard, D. (2008) Digital technologies and their role in achieving our educational ambitions. Professorial lecture, Institute of Education, University of London, 28 February 2008.

[22] Levin, D. and Arefeh, S. (2002) The digital disconnect: The widening gap between internet-savvy students and their schools. http://ebookbrowse.com/gdoc.php?id= 233755856\&url=594ad9121f3c8b3b8f56e4f0064a9489 [last accessed 12 June 2012]

[23] Lui, X., Lee, S. H., Bonk, C. J., Magjuka, R. J. and Liu, S. (2007) Technology use in an online MBA program: Issues, trends and opportunities. In Kidd, T. and Song, H. (Eds.) Handbook of Research on Instructional Systems and Technology (p. 614-630). Hershey, PA: Information Science Reference.

[24] MacKeogh, K. and Fox, S. (2009) Strategies for embedding elearning in traditional universities: Drivers and barriers. Electronic Journal of E-Learning, 7, 2, 147-154.

[25] Matthew, K. I., Parker, R. and Wilkinson, L. (1998) Faculty adoption of technology: Stages of concern. Paper presented at the Society of Information Technology in Teacher Education Conference, Washington, DC.

[26] McWilliam, E. (2008) Unlearning how to teach. Innovations in Education and Teaching International, 45, 3, 263-69 http://dx.doi.org/10.1080/14703290802176147

[27] Muirhead, W.D. (2000) Online education in school. The international Journal of Educational Management, 14, 7, 315-324. http://dx.doi.org/10.1108/09513540010378969

[28] Oren A., Mioduser, D. and Nachmias, R. (2002) The Development of Social Climate in Virtual Learning Discussion Groups, The International Review of Research in Open and Distance Learning, 3, 1.

[29] Owusu-Ansah, A., Neill, P. and Haralson, M. (2011) Distance Education Technology: Higher Education Barriers During the First Decade of the Twenty-First Century. Online Journal of Distance Learning Administration, 14, 2. 
[30] Palloff, R. M. and Pratt, K. (1999) Building learning communities in cyberspace: Effective strategies for online classrooms. San Francisco, CA: Jossey-Bass.

[31] Pankoski, P. (2004) Faculty training for online teaching. THE Journal. $\quad$ http://thejournal.com/articles/2004/09/01facualtytraining-for-online-teaching.aspx [last accessed 12 June 2012]

[32] Patton, M. (2001). Qualitative evaluation and research methods ( $3^{\text {rd }}$ ed.). Thousand Oaks: Sage.

[33] Phillips, R, McNaught, C. and Kennedy, G. (2012) Evaluating elearning: guiding research and practice. London: Routledge.

[34] Picciano, A. (2001) Distance Learning: Making connections across virtual space and time. Upper Saddle River, NJ: Merrill Prentice Hall.

[35] Piotrowski, C. and Vodanovich, S. J. (2000) Are the reported barriers to the internet-based instruction warranted? A synthesis of recent research. Education, 121, 1, 48-53.

[36] Puzziferro, M. and Shelton, K. (2009) Supporting Online Faculty - Revisiting the Seven Principles (A Few Years Later). Online Journal of Distance Learning Administration, 12, 3.

[37] Robinson, J. P., Shaver, P. R., \& Wrightsman, L. S. (Eds). (1991). Measures of personality and social psychological attitudes. San Diego, CA: Academic Press.

[38] Salmon, G. (2003) E-moderating: The key to teaching and learning online. London: Kogan Page.

[39] Shea, P., Pickett, A. and Li, C. (2005) Increasing access to higher education: A study of the diffusion of online teaching among 913 college faculty. International Review of Research in Open and Distance Learning, 6, 2.

[40] Shulman, L. (1986) Those who understand: Knowledge growth in teaching. Educational Researcher, 15, 2, 4-14.

[41] Siemens, G. (2004) Connectivism: A learning theory for the digital age. http://www.elearnspace.org/Articles/connectivism.htm [last accessed 12 June 2012]
[42] Surowieki, J. (2005) Independent individuals and wise crowds: is it possible to be too connected? IT Conversations, 468. [http://itc.conversationsnetwork.org/ shows/detail468.html]

[43] Volery, T. (2000) Critical success factors in online education. The International Journal of Educational Management, 14, 5, 216223. http://dx.doi.org/10.1108/09513540010344731

[44] Weiger, P.R. (1998) What a tangle (world wide) web we weave. Community College Week, 10, 22, 11-13.

[45] Yang, Y. and Cornelious, L. F. (2005) Preparing Instructors for Quality Online Instruction. Online Journal of Distance Learning Administration, 8, 1.

[46] Zirkle, C., Norris, C., Ainegardner, A. and Frustaci, E. (2006) Distance education programming in business education teacher preparation programs in the United States. Career and Technical Education Research, 31, 2, 101-118. http://dx.doi.org/10.5328/ CTER31.2.101

\section{AUTHORS}

P. Cowan is a Lecturer in E-learning with the School of Education, Queen's University Belfast, 69-71 University Street, BELFAST, BT7 1HL, UK. (p.cowan@qub.ac.uk).

P. S. Neil is Head of the School of Education, University of West Scotland, Ayr Campus , University Avenue, AYR, KA8 0SX, Scotland. (peter.neil@uws.ac.uk).

E. Winter is the Director of Academic Programmes at the Institute of Child Education and Psychology, Europe (e.winter@icepe.eu).

This work was supported by the Higher Education Academy for Education in the UK (ESCalate). Received 08 November 2012. Published as resubmitted by the authors 27 February 2013. 